\title{
OS EFEITOS DA PANDEMIA DA COVID-19 NO TRIBUNAL DE JUSTIÇA DO CEARÁ: REPERCUSSÕES SOBRE A TEMPESTIVIDADE PROCESSUAL NAS CÂMARAS CRIMINAIS ${ }^{1}$
}

\section{THE EFFECTS OF COVID-19 PANDEMIC AT CEARÁ COURT OF JUSTICE:} REPERCUSSIONS ON THE PROCESSUAL TIMING IN CRIMINAL CHAMBERS

José Victor Ibiapina Cunha Morais Especialista em Direito e Processo Penal pelo Centro Universitário Sete de Setembro - Uni7. Graduado em Direito pela Universidade de Fortaleza - UNIFOR. Pesquisador do Projeto Pesquisa Empírica em Direito (Cnpq) vinculado ao curso de Direito da Universidade de Fortaleza - UNIFOR. Coordenador da $1^{\text {a }}$ Câmara Criminal do TJ/CE. Fortaleza/CE. E-mail: victoribiapinacunha@ hotmail.com

Mariana Dionísio de Andrade Doutora em Ciência Política pela Universidade Federal de Pernambuco. Mestre em Direito Constitucional pela Universidade de Fortaleza - UNIFOR. Especialista em Direito Processual Civil pela UNIFOR. Professora do Curso de PósGraduação lato sensu em Direito e Processo Constitucionais e da disciplina Teoria Geral do Processo Civil no Curso de Graduação em Direito na Universidade de Fortaleza. Formação em Leadership and Conflict Management pela Stanford University. Formação em Métodos Quantitativos pela UERJ. Pesquisadora do Grupo Epistemologia e Método na Ciência Política Comparada (Cnpq/UFPE). Coordenadora do Projeto Pesquisa Empírica em Direito (Cnpq/ UNIFOR). Pesquisadora do Laboratório de Ciências Criminais -

\footnotetext{
${ }^{1}$ Artigo recebido em 16/09/2020 e aprovado em 16/12/2020.
} 
LACRIM (Cnpq/UNI- FOR). Advogada. Fortaleza/CE. Email: mariana.dionisio@unifor.br

RESUMO: O estudo procura responder ao seguinte problema de pesquisa: o Tribunal de Justiça do Ceará tem realizado medidas adequadas para garantir a produtividade e a prestação jurisdicional efetiva das Câmaras Criminais em tempos da Pandemia do Covid19? A pesquisa possui abordagem qualitativa, exploratória e bibliográfica; além de suporte quantitativo com dados secundários, correspondentes à produtividades das Câmaras Criminais. Conclui-se que as medidas foram eficazes porque além da manutenção da produtividade, as Câmaras Criminais aumentaram o quantitativo de julgamentos durante a pandemia, comparativamente ao mesmo período do ano anterior.

PALAVRAS-CHAVE: Pandemia do Covid-19. Teletrabalho. Tribunal de Justiça do Ceará. Tempestividade processual.

ABSTRACT: The study aims to answer the following research problem: has the Ceará Court of Justice carried out adequate measures to guarantee the productivity and the effective jurisdictional provision of the Criminal Chambers in a scenario of Covid-19 Pandemic? The research has a qualitative, exploratory and bibliographic approach; in addition to quantitative support with secondary data, corresponding to the productivity of the Criminal Chambers. It is concluded that the measures were effective because in addition to maintaining productivity, the Criminal Chambers increased the number of trials during the pandemic, compared to the same period last year.

KEYWORDS: Covid-19 pandemic. Teleworking. Ceará Court of Justice. Procedural timing.

\section{INTRODUÇÃO}

O presente trabalho procura responder ao seguinte problema de pesquisa: as ações do Tribunal de Justiça do Ceará têm sido eficazes para garantir a produtividade e a prestação jurisdicional efetiva das Câmaras Criminais em tempos da Pandemia do 
Convid-19? Assim, visa identificar as principais ações implementadas pelo Tribunal de Justiça do Ceará para garantir a continuidade da prestação jurisdicional pelos órgãos colegiados de natureza criminal.

Para responder ao problema, utiliza-se de uma metodologia de pesquisa mista, mesclando natureza qualitativa, com abordagem bibliográfica, exploratória e documental, na medida em que serão desenvolvidos os conceitos pertinentes ao tema para melhor compreensão do assunto estudado, a partir de artigos científicos afetos ao tema, documentos legais que regulamentem os assuntos abordados; bem como suporte complementar de natureza quantitativa, com dados secundários obtidos via consulta pelo TJCE, uma vez que foram analisadas informações correspondentes à produtividades das Câmaras Criminais (em caráter colegiado) mediante solicitação aos canais de atendimentos disponibilizados, sendo informações organizadas e compiladas pelas respectivas unidade judiciais, além de dados analisados e desenvolvidos sobre a viabilidade e satisfatividade do teletrabalho.

No primeiro tópico, aborda-se a propagação do coronavírus, os reflexos das medidas de combate pelo Brasil e especificamente no Estado do Ceará, no âmbito executivo e judicial. O segundo tópico se presta a identificar as principais medidas implementadas pelo Tribunal de Justiça do Ceará diante da pandemia, para a manutenção dos índices de produtividade e da continuidade da prestação jurisdicional, destacando-se dentre elas a adoção o teletrabalho, informações obtidas através dos atos normativos editados pela referida instituição e pelo Conselho Nacional de Justiça (CNJ). Ainda neste tópico, são destacados os pontos que suscitam dúvidas acerca do teletrabalho e sua viabilidade, denotando os aspectos positivos e negativos a partir de dados extraídos de estudos anteriores que analisaram tais aspectos em diversos órgãos públicos brasileiros.

São desenvolvidos os conceitos referentes à tempestividade processual, celeridade e razoável duração do processo, evidenciando sua relação com a efetividade da prestação judicial, para compreender se as ações desenvolvidas pelo TJCE se mostram adequadas para atingir seu escopo de continuidade do serviço judicante sem prejuízo pelo estado pandêmico. Por último, serão analisados os dados obtidos junto as Secretarias de Câmaras Criminais $\left(1^{\mathrm{a}}, 2^{\mathrm{a}}\right.$ e $\left.3^{\mathrm{a}}\right)$ do TJCE, referentes à produtividade dos Órgãos Colegiados comparando-os por amostragem de período de tempos equivalentes. O primeiro deles é 
referente ao primeiro semestre de 2020 no qual o Tribunal atuou em meio à pandemia comparando-o com o segundo período, referente ao primeiro semestre de 2019 no qual houve a atuação em regime forense normal, para ao fim, chegar a uma resposta ao problema de pesquisa formulado.

A pesquisa é relevante em termos teóricos porque oferece um contributo inédito para o tema e, sob uma perspectiva prática, se destaca por evidenciar a realidade específica do Tribunal de Justiça do Estado do Ceará, auxiliando outros tribunais pela identificação de medidas efetivas e consistentes ao combate à morosidade em tempos de pandemia e demonstrando para o Poder Judiciário nacional as alternativas encontradas por um dos tribunais mais produtivos do país.

\section{A PANDEMIA DO COVID-19 E DADOS EM NÚMEROS NO BRASIL E NO MUNDO: PRIMEIROS DESDOBRAMENTOS DO ISOLAMENTO SOCIAL NO CEARÁ}

O ano de 2020 foi marcado por um fato que permanecerá por muito tempo na memória coletiva, seja em razão das profundas mudanças de hábitos causadas nas relações pessoais ou pelos impactos econômicos e políticos. Talvez seja cedo para dizer se haverá ou não alterações definitivas na vida das pessoas, mas é possível afirmar com muita precisão, que os impactos ao longo do ano de 2020 foram profundos e duradores.

O Covid-19 consiste em uma classe de vírus que atinge o sistema respiratório humano (coronavírus) já existente como causador da gripe comum (resfriado), em um estágio evoluído descoberto no ano de 2019 (por isso a denominação "Covid-19") conferida pela Organização Mundial da Saúde (OMS). Foi inicialmente detectado na China, na província de Hubei onde os primeiros pacientes apresentaram um quadro de pneumonia grave e desconhecida ${ }^{2}$.

O ritmo de contágio do patógeno é extremamente elevado e acelerado, provocando uma disseminação ao redor do mundo o que denota a gravidade da situação, corroborado com as informações divulgadas e organizadas pela Organização das Nações

\footnotetext{
${ }^{2}$ ROTHAN, Hussin A.; BYRAREDDY, Siddappa N. The epidemiology and pathogenesis of coronavirus disease (COVID-19) outbreak. Journal of Autoimmunity. 2020, p. 1-4
} 
Unidas (ONU) e cuja circunstância evoluiu em janeiro de 2020 para uma situação de Emergência de Saúde Pública de Importância Internacional (ESPII) conforme relatório da Organização Pan-Americana de Saúde (OPAS) ${ }^{3}$, objetivando com essa categorização uma uniformidade na implementação de medidas que pudessem combater a situação.

A Organização Mundial da Saúde tem divulgado uma série de documentos que relatam a proliferação da Covid-19 em nível global, traçando estratégias de combate e prevenção à disseminação do vírus, dentre elas, identificar pacientes contaminados para trata-los e isolá-los, combater a desinformação e a interrupção de contato humano, incentivar o isolamento social como forma para evitar o contato entre pessoas a partir do convívio social ${ }^{4}$.

No caso do Ceará, o Governo do Estado (Poder Executivo) através do Decreto n 33.513 de 16 de março de 2020, estabeleceu situação de emergência em saúde decorrente do novo Covid-19 (art. $1^{\circ}$ ), impondo a necessidade de articulação de ações e serviços de saúde voltados à contenção da situação de emergência, competindo à Secretaria de Saúde a coordenação das ações de enfrentamento ao novo coronavírus (Covid-19) no âmbito do Estado (art. 2).

Diante da situação de emergência na saúde no Ceará, foi editado o Decreto $\mathrm{n}^{\circ}$ 33.519, que intensificou as medidas de restrição previstas no Decreto n. ${ }^{\circ}$ 33.510, de 16 de março de 2020, suspendendo em todo o território estadual o funcionamento de diversos segmentos da economia e da cadeia produtiva.

Nessa perspectiva, o Poder Judiciário do Estado do Ceará, acompanhando as primeiras medidas de isolamento social adotados pelo Poder Executivo, editou a Portaria n 514 datada de 21 de março de 2020 levando em consideração a "Declaração de Emergência em Saúde Pública de Importância Internacional” pela Organização Mundial da Saúde, em decorrência da Infecção Humana pelo novo coronavírus e a pandemia da Covid-19 regulamentando, no âmbito do Poder Judiciário do Estado do Ceará, o regime de Plantão Extraordinário objetivando prevenir o contágio pelo novo coronavírus Covid-19 (artigo $1^{\circ}$ ) instituindo assim, o regime obrigatório de teletrabalho para

\footnotetext{
${ }^{3}$ OPAS BRASIL. Organização Pan-Americana de Saúde. Folha informativa - COVID-19 (doença causada pelo novo coronavírus). 23 de abril de 2020. Disponível:

https://www.paho.org/bra/index.php?option=com_content\&view=article\&id=6101:Covid19\&Itemid=875. Acesso em: 11 de julho de 2020.

${ }^{4}$ World Healthy Organization, op.cit.
} 
magistrados, servidores, estagiários e demais colaboradores do Poder Judiciário do Estado do Ceará, em idêntico horário ao do expediente forense regular ${ }^{5}$.

A partir da edição do referido ato normativo, o Tribunal de Justiça do Ceará editou uma série de outros atos regulamentando a modalidade de funcionamento do teletrabalho no âmbito do Poder Judicial local, bem como uma diversidade de medidas voltadas à manutenção da produtividade com ênfase no aprimoramento do teletrabalho.

\section{AS MEDIDAS ADOTADAS PELO TRIBUNAL DE JUSTIÇA DO CEARÁ PARA MANTER A PRODUTIVIDADE EM MEIO À PANDEMIA DO COVID-19}

A pandemia do Covid-19 impôs a necessidade de readequação das instituições públicas e privadas quanto ao exercício de suas respectivas atividades adotando medidas para dar continuidade à prestação de serviços adaptando-se à uma realidade de distanciamento social necessário com vistas a impedir a disseminação da doença.

Com o Poder Judiciário no Brasil a situação não se mostrou diferente, demandando de todas as instâncias medidas que possibilitam essa adequação. Assim, é preciso evidenciar algumas medidas adotadas pelo Tribunal de Justiça do Ceará, no âmbito do $2^{\circ}$ Grau de Jurisdição, para manter a continuidade do exercício da atividade jurisdicional e consequentemente sua produtividade, com enfoque naquelas mais atinentes ao objeto de estudo do presente trabalho.

Para a pesquisa, a escolha do TJCE como unidade de análise se justifica pela acessibilidade aos dados e por se tratar de uma instituição de referência em termos de produtividade. De acordo com o Relatório Justiça em Números do Conselho Nacional de Justiça 2020, ano base 2019, o Índice de Produtividade dos Magistrados (IPM) do TJCE ocupa a $13^{\mathrm{a}}$ posição no ranking nacional da Justiça Estadual, possui indicadores relevantes de redução nas Taxas de Congestionamento, ocupa o $14^{\circ}$ lugar no ranking

\footnotetext{
${ }^{5}$ CEARÁ. Portaria no 514, de 23 de março de 2020. Regulamenta, no âmbito do Poder Judiciário do Estado do Ceará, o regime de Plantão Extraordinário, estabelecido pela Resolução n ${ }^{\circ} 313$, de 19 de março de 2020, do Conselho Nacional de Justiça.. Portaria N 514. Fortaleza, CE, 23 mar. 2020.
} 
nacional do Índice de Atendimento à Demanda (IAD), além de se destacar quanto à versação adequada do orçamento ${ }^{6}$.

\subsection{Teletrabalho e as Sessões de Julgamento por videoconferência}

As medidas adotadas pelos Tribunais de Justiça e pontualmente pelo TJCE, são pautadas nas orientações emanadas pelo Conselho Nacional de Justiça (CNJ) que tem expedido atos normativos disciplinando a atuação de todo o Poder Judiciário, por ser um órgão de caráter administrativo e fiscalizador, cabendo a ele disciplinar de maneira geral a atuação do Judiciário, conforme mandamento constitucional contido no artigo 103-B, § $4^{\mathrm{o}}$ da $\mathrm{CF} / 88$, cabendo aos demais órgãos adequarem as normas gerais às suas respectivas realidades e especificidades.

Um dos primeiros atos regulamentadores foi a Resolução no 313 de 19 de março de 2020, do Conselho Nacional de Justiça, cujo texto estabeleceu no âmbito do Poder Judiciário, o regime de Plantão Extraordinário, uniformizando o funcionamento dos serviços judiciários, com o objetivo de prevenir o contágio pelo novo Coronavírus Covid-19, e garantir o acesso à justiça em um período atípico considerado emergencial ${ }^{7}$.

O Plantão Extraordinário a que aduz a Resolução nº 313/2020 consiste em uma modalidade de funcionamento do Poder Judiciário em horário equivalente ao do expediente forense regular, estabelecido pelo respectivo Tribunal, mas que traz uma especificidade: a suspensão do trabalho presencial de magistrados, servidores, estagiários e demais colaboradores das respectivas unidades de toda a estrutura do Judiciário, assegurando a manutenção dos serviços essenciais em cada Tribunal ${ }^{8}$. A norma

\footnotetext{
6 CNJ. Conselho Nacional de Justiça. Relatório Justiça em Números 2020. Disponível em: <https://www.cnj.jus.br/wp-content/uploads/2020/08/WEB-V3-Justiça-em-Números-2020-atualizado-em-2508-2020.pdf >. Acesso em: 01 set. 2020.

${ }^{7}$ BRASIL. Resolução no 313, de 19 de março de 2020. Estabelece, no âmbito do Poder Judiciário, regime de Plantão Extraordinário, para uniformizar o funcionamento dos serviços judiciários, com o objetivo de prevenir o contágio pelo novo Coronavírus - Covid-19, e garantir o acesso à justiça neste período emergencial. Resolução $\quad \mathbf{N}^{\mathbf{0}}$ 313. Brasília, DF, 19 mar. 2020. Disponível em: https://atos.cnj.jus.br/atos/detalhar/3249. Acesso em: 20 jul. 2020

${ }^{8}$ BRASIL. Resolução no 313, de 19 de março de 2020. Estabelece, no âmbito do Poder Judiciário, regime de Plantão Extraordinário, para uniformizar o funcionamento dos serviços judiciários, com o objetivo de prevenir o contágio pelo novo Coronavírus - Covid-19, e garantir o acesso à justiça neste período emergencial. Resolução $\quad \mathbf{N}^{\mathbf{0}}$ 313. Brasília, DF, 19 mar. 2020. Disponível em: https://atos.cnj.jus.br/atos/detalhar/3249. Acesso em: 20 jul. 2020.
} 
suspendeu o atendimento presencial aos jurisdicionados assegurando o canal remoto para tais fins (artigo $3^{\circ}$ ) suspendendo ainda os prazos processuais (artigo $5^{\circ}$ ), autorizando os respectivos tribunais a disciplinarem o trabalho remoto de seus colaboradores bem como a realização de sessões virtuais de julgamento de processos $\left(\operatorname{artigo} 6^{\circ}\right)^{9}$.

A Resolução $\mathrm{n}^{\circ} 314$ de 20 de abril de 2020, do CNJ, trouxe maiores regulamentações a respeito do Plantão Extraordinário, além de prorrogar o regime instituído ${ }^{10}$, retomando os prazos processuais de processos virtuais e regulando mais especificamente o funcionamento da sessões virtuais de julgamento nos tribunais e turmas recursais do sistema de Juizados Especiais, realizadas na modalidade de julgamento por videoconferência, substituindo as sessões presenciais ${ }^{11}$.

O Plantão Extraordinário do TJCE foi regulamentado pela Portaria $n^{\circ} 514 / 2020$ através da qual foi instituído o regime obrigatório aos servidores, magistrados e demais colaboradores de teletrabalho no período de expediente forense, suspendendo os atendimentos presenciais garantindo sua continuidade através de via remota ${ }^{12}$. O portal eletrônico do tribunal também disponibilizou uma rede de contatos de teletrabalho, por telefone ou e-mail, para todas as comarcas do Estado, facilitando o acesso às informações para profissionais do direito e jurisdicionados.

Em complemento à norma acima e para dar continuidade ao exercício de sua atividade judicante colegiada, o TJCE editou a Portaria $n^{\circ} 563 / 2020$, regulamentando a realização de julgamento por videoconferência ${ }^{13}$, revogada posteriormente pela Portaria n $635 / 2020$ (em vigência até o momento), mantendo a realização das sessões de julgamento ordinárias e extraordinárias por videoconferência, em substituição às sessões

\footnotetext{
${ }^{9}$ Ibid.

${ }^{10} \mathrm{O} \mathrm{CNJ}$ editou ainda outras normas que prorrogam e fizeram alterações no Regime Extraordinário acima mencionado, sendo essas as mais elementares para serem mencionadas no desenvolvimento dessa pesquisa (Portaria $\mathrm{n}^{\circ}$ 79, de 22 de maio de 2020. (Prorrogou o prazo); Resolução $\mathrm{n}^{\circ} 318$, de 7 de maio de 2020. (Prorrogou o prazo); Resolução n 314 , de 20 de abril de 2020.

${ }^{11}$ BRASIL. Resolução no 314, de 20 de abril de 2020. Prorroga, no âmbito do Poder Judiciário, em parte, o regime instituído pela Resolução no 313, de 19 de março de 2020, modifica as regras de suspensão de prazos processuais e dá outras providências.. Resolução $\mathbf{N}^{\mathbf{0}}$ 314. Brasília, DF, 20 abr. 2020. Disponível em: https://atos.cnj.jus.br/atos/detalhar/3283. Acesso em: 20 jul. 2020

${ }^{12}$ CEARÁ. Portaria $\mathrm{n}^{\circ}$ 514, de 23 de março de 2020. Regulamenta, no âmbito do Poder Judiciário do Estado do Ceará, o regime de Plantão Extraordinário, estabelecido pela Resolução n 313, de 19 de março de 2020, do Conselho Nacional de Justiça.. Portaria N 514. Fortaleza, CE, 23 mar. 2020.

13 CEARÁ. Portaria $n^{\circ} 563$, de 31 de março de 2020. Autoriza a realização de sessão de julgamento por videoconferência no âmbito do Poder Judiciário do Estado do Ceará.. Portaria Nº 563. Fortaleza, CE, 31 mar. 2020 .
} 
presenciais, assegurando ainda a publicidade dos atos através de transmissão pela internet ${ }^{14}$.

As sessões de julgamento em regime de expediente forense normal, antes realizadas de maneira presencial, foram substituídas pelo modelo de videoconferência. As sessões ocorrem remotamente, e para o julgamento dos processos, a norma estabelece a utilização, no que couber, dos regramentos contidos na Resolução $n^{\circ}$ 26/2018 do TJCE, que disciplina a ferramenta do voto provisório.

Essa ferramenta consiste em uma modalidade de julgamento de processos nos órgãos colegiados através da qual os desembargadores relatores disponibilizam suas minutas (decisão) de cada processo previamente à sessão de julgamento, e os demais desembargadores integrantes da câmara julgadora manifestam seu juízo de convicção acerca do tema, podendo acompanhar o entendimento do relator ou discordar. Os julgamentos são levados posteriormente à sessão para convalidação dos respectivos resultados ${ }^{15}$. Assim, a utilização dessa ferramenta possibilita que os desembargadores tenham acesso remotamente aos processos manifestando o seu livre convencimento motivado sobre o caso, sem prejuízo de uma análise acurada.

Observe-se que esse regime de Plantão Extraordinário, como visto na Portaria $\mathrm{n}^{\circ}$ 514 do TJCE, é feito através do teletrabalho. Essa modalidade de trabalho configura uma das principais medidas adotadas pelo Tribunal de Justiça do Ceará para a manutenção da prestação jurisdicional e, consequentemente, de sua produtividade. Contudo, essa modalidade suscita dúvidas acerca de sua viabilidade, notadamente por ainda não ser amplamente conhecida.

\subsection{Teletrabalho: conceito, vantagens e desvantagens}

\footnotetext{
${ }^{14}$ CEARÁ. Portaria $n^{\circ}$ 635, de 22 de abril de 2020. Autoriza a realização de sessão de julgamento por videoconferência, em substituição às sessões presenciais, no âmbito do Poder Judiciário do Estado do Ceará.. Portaria No 635. Fortaleza, CE, 22 abr. 2020.

15 CEARÁ. Resolução $\mathrm{n}^{\circ}$ 26, 04 de outubro de 2018. Disciplina o funcionamento do voto provisório no âmbito do Poder Judiciário do Estado do Ceará. Fortaleza. Disponível em: https://sistemasinternet.tjce.jus.br/includes/mostraAnexo.asp?san=24584. Acesso em: 23 jun. 2020.
} 
O teletrabalho tem se manifestado como uma modalidade de exercício das atividades laborais com difusão pelo mundo nas mais diversas organizações, sejam elas públicas ou privadas, muitas vezes se revelando como uma alternativa viável para a continuidade da prestação de serviços com menor custo de expediente envolvido.

Diante da pandemia da Covid-19, o mundo experimentou um avanço forçado dessa modalidade, condicionado pela circunstância do isolamento social. No Brasil, não foi diferente: tanto nos setores públicos quanto privados, houve maior atenção para a adoção do teletrabalho, notadamente no Poder Judiciário, cuja adesão se verificou em todas as esferas hierárquicas ( $1^{\circ}$ grau, $2^{\circ}$ grau de jurisdição e instâncias extraordinárias).

Há anos são realizados estudos acerca da viabilidade dessa modalidade nas diferentes categorias de serviços e atividades, o que gera diferentes perspectivas para trabalhadores e empregadores. Assim, desenvolver essa ideia no presente tópico é essencial para a compreensão do fenômeno estudado, para evidenciar o teletrabalho como uma ferramenta adequada ou não à manutenção da produtividade do Poder Judiciário do Ceará durante a pandemia da Covid-19 que impossibilitou a continuidade do exercício das atividades nos moldes tradicionais.

Importante salientar as discussões acerca da eficiência e do desempenho da administração pública, que sofre críticas veementes acerca de seu tamanho e legitimidade, na proporção em que a sociedade exige serviços públicos cada vez mais rápidos e de qualidade, encontrando no uso das tecnologias de informação e comunicação (TICs) uma ferramenta eficaz para a concreção desse ideal de Poder Público produtivo, com a maior eficiência possível ${ }^{16}$.

Essas tecnologias adquiriram especial importância nesse período de pandemia. Para uma melhor compreensão, é necessário inicialmente esclarecer que a modalidade de teletrabalho corresponde "a todo trabalho realizado à distância, fora do local de trabalho, com uso das TICs, com computadores, telefonia fixa e celular e toda tecnologia que

\footnotetext{
${ }^{16}$ FILARDI, Fernando; CASTRO, Rachel Mercedes P.. DE; ZANINI, Marco Tulio Fundão. Vantagens e desvantagens do teletrabalho na administração pública: análise das experiências do Serpro e da Receita Federal. Cad. EBAPE.BR, Rio de Janeiro, v. 18, n. 1, p. 28-46, Jan. 2020 . Disponível em http://www.scielo.br/scielo.php?script=sci_arttext\&pid=S1679-39512020000100028\&lng=en\&nrm=iso. Acesso em: 07 agosto 2020., p. 29-46.
} 
permita trabalhar em qualquer lugar, receber e transmitir informações, arquivos, imagens ou som relacionados à atividade laboral" ${ }^{\prime 17}$.

Embora essa definição não guarde uniformidade (ganhando diferentes denominações populares como home office, trabalho remoto, trabalho a distância, dentre outros), vez que apresenta diferentes perspectivas e espécies de teletrabalho, todas essas modalidades guardam entre si aspectos similares, tais como a flexibilização dos espaços de trabalho, do tempo dedicado a ele e a substituição do deslocamento do trabalhador até a sede demandante pelo uso das ferramentas de informação e comunicação remota ${ }^{18}$.

O teletrabalho é considerado como um componente importante das mudanças na sociedade, contudo, suas potencialidades revestem-se de um caráter dúbio, podendo ser encarado até mesmo como contraditório na medida em que suas consequências podem ser também prejudiciais. A exemplo dos trabalhadores de baixa qualificação localizados em regiões e países de baixo grau de desenvolvimento que apresentam uma forma de teletrabalho diferente dos trabalhadores de alta qualificação, na medida em que para um pode haver flexibilidade real, enquanto que para o outro grupo poderá haver apenas um aumento de controle por conta da automatização ${ }^{19}$.

Quando analisada no contexto da administração pública, a existência de diferentes graus de qualificação técnica não se mostra como uma das grandes desvantagens assinaladas pelos trabalhadores, mas exsurgem diversos fatores que merecem ser levados em consideração, como a falta de regulação e fiscalização, o que pode gerar prejuízos ao trabalhador, como dificuldades na ergonomia, dificuldades com a organização entre trabalho e rotinas familiares, dilatação da jornada de trabalho sem a devida remuneração ou problemas de saúde decorrentes do excesso de uso de telas.

Por outro lado, há instituições que se adequaram ao teletrabalho, como o Serviço Federal de Processamento de Dados (Serpro), com sede em Brasília e presente em 11

\footnotetext{
17 Ibid.

${ }^{18}$ ROCHA, Cháris Telles Martins da; AMADOR, Fernanda Spanier. O teletrabalho: conceituação e questões para análise. Cad. EBAPE.BR, Rio de Janeiro , v. 16, n. 1, p. 152-162, Jan. 2018 . Disponível em: http://www.scielo.br/scielo.php?script=sci_arttext\&pid=S1679-39512018000100152\&lng=en\&nrm=iso. Acesso em: 07 agosto 2020, p. 154-162.

19 SAKUDA, Luiz Ojima; VASCONCELOS, Flávio de Carvalho. Teletrabalho : desafios e perspectivas. Organ. Soc., Salvador , v. 12, n. 33, junho 2005. Disponível em: http://www.scielo.br/scielo.php?script=sci_arttext\&pid=S1984- $\quad 92302005000200002 \& \operatorname{lng}=\mathrm{en} \& \mathrm{nrm}=\mathrm{iso}$. Acesso em: 10 agosto 2020, p. 45-49.
} 
capitais; Tribunal de Contas da União do Distrito Federal (TCU-DF); Tribunal Regional do Trabalho da Paraíba (TRT-PB); Tribunal de Justiça de São Paulo (TJSP); e Receita Federal, com sedes em Brasília e no Rio de Janeiro, conforme evidencia o estudo "Vantagens e desvantagens do teletrabalho na administração pública: análise das experiências do Serpro e da Receita Federal" ${ }^{\text {,20. }}$.

A análise quantitativa do referido estudo consistiu em aplicar questionário a 98 teletrabalhadores, para verificar possíveis desvantagens para o desenvolvimento do teletrabalho, como o custo de equipamentos, dificuldades organizacionais, falta de infraestrutura, falta de treinamento específico para o teletrabalho, necessidade de montar estrutura em casa, mudanças na estrutura organizacional e tecnologia ainda sem a performance esperada (indicadores estruturais). O estudo identificou que 81,6\% dos trabalhadores respondentes discordam da falta de estrutura para o teletrabalho, 50\% concordam que houve treinamento para o teletrabalho, outros $33,6 \%$ discordam que houve treinamento adequado, o que revela um ponto de atenção já que o treinamento pode ajudar a reduzir a insegurança gerada pela nova forma de trabalho adotada. Já sobre a tecnologia disponível ao uso dos servidores $85,7 \%$ a consideram adequada ${ }^{21}$.

Já os indicadores profissionais ${ }^{22}$, nos quais os aspectos de autonomia, motivação, flexibilidade, produtividade e qualidade do trabalho apareceram com nível de concordância elevado, entre 74 e $94 \%$ dos respondentes consideram que nesses quesitos obtiveram ganhos, em via oposta ao crescimento e desenvolvimento no órgão, na medida em que $23,4 \%$ e $14,3 \%$, respectivamente, concordam que crescer e desenvolver-se ficou mais difícil depois do teletrabalho ${ }^{23}$.

Quando analisados conflitos entre trabalho e vida familiar (indicadores psicológicos) revela-se que os teletrabalhadores dos órgãos públicos estudados não sentem dificuldades de concentração, prejuízo da vida social, nem conflito trabalho

\footnotetext{
${ }^{20}$ FILARDI, Fernando; CASTRO, Rachel Mercedes P.. DE; ZANINI, Marco Tulio Fundão, op. cit.

21 Ibid.

${ }^{22}$ Crescimento na empresa; Dificuldade de controle; Dificuldade de desenvolvimento; Dificuldade de motivação; Erros de seleção de tarefa; Falta de reconhecimento dos colegas de trabalho; Falta de supervisão; Isolamento profissional; Maior cobrança; Não adequação ao teletrabalho; Percepção de perda de status; Receio de má avaliação ${ }^{23}$ FILARDI, Fernando; CASTRO, Rachel Mercedes P.. DE; ZANINI, Marco Tulio Fundão, op. cit.
} 
versus vida familiar, já que os resultados desses aspectos ficaram acima dos $80 \%$ de concordância positiva para esses critérios ${ }^{24}$.

Assim, percebe-se que as principais circunstâncias comumente vistas como elementos negativos do teletrabalho não representam uma opinião uníssona dos teletrabalhadores, pelo contrário; os dados mostram a adequação do teletrabalho à realidade do Poder Público.

Rocha e Amador ${ }^{25}$ apontam ainda como vantagens e desvantagens para o teletrabalho, respectivamente, a flexibilização da jornada de trabalho; a organização do tempo de modo a melhor conciliar demandas sociais, familiares, laborais e de lazer; à economia de tempo com transporte casa-trabalho; e a autonomia para organização do modo de trabalhar, principalmente no que diz respeito ao espaço e ao tempo; e quanto às organizações ou empresas as vantagens e desvantagens são, a redução de custos com espaço físico, equipamentos e manutenção; o aumento da produtividade; a diminuição do absenteísmo; e a retenção de talentos.

Esse panorama segue a tendência de forte aceitação mundial dessa modalidade de trabalho, que denota um acelerado crescimento, com países que já reconhecem e regulamentam a prática do teletrabalho como Portugal, Itália, Espanha, França, Finlândia, EUA, Argentina e Chile, possuindo legislações específicas a respeito do tema e bem como regulamentações estabelecidas pela União Europeia ${ }^{26}$. No Brasil, a legislação afeta ao tema ainda se mostra escassa e pouco aprofundada, uma vez que concentra sua regulamentação na Lei $n^{\circ}$ 13. 467/2017 e no artigo $6^{\circ}$ da Consolidação das Leis do Trabalho, cuja redação foi dada pela Lei $\mathrm{n}^{\circ}$ 12.551/2011, ao equiparar a vinculação jurídica do trabalho realizado presencialmente ao realizado a distância ${ }^{27}$.

\footnotetext{
${ }^{24}$ Ibid.

${ }^{25}$ ROCHA, Cháris Telles Martins da; AMADOR, Fernanda Spanier. O teletrabalho: conceituação e questões para análise. Cad. EBAPE.BR, Rio de Janeiro, v. 16, n. 1, p. 152-162, Jan. 2018 . Disponível em: http://www.scielo.br/scielo.php?script=sci_arttext\&pid=S1679-39512018000100152\&lng=en\&nrm=iso. Acesso em: 07 agosto 2020, p. 156-162.

${ }^{26}$ Ibid.

${ }^{27}$ Art. 6o Não se distingue entre o trabalho realizado no estabelecimento do empregador, o executado no domicílio do empregado e o realizado a distância, desde que estejam caracterizados os pressupostos da relação de emprego. Parágrafo único. Os meios telemáticos e informatizados de comando, controle e supervisão se equiparam, para fins de subordinação jurídica, aos meios pessoais e diretos de comando, controle e supervisão do trabalho alheio. (BRASIL, 2011)
} 
Em outra pesquisa voltado ao tema do teletrabalho, foi estudado o caso da empresa Yahoo, uma das primeiras em nível global a aderirem ao regime de teletrabalho. Contudo, inobstante a necessidade pela realização de uma carga e demanda de trabalho específicas feitas na empresa (em regime presencial) é esperado que haja um envolvimento entre pessoas, interrelação entre colaboradores com impacto direto na produtividade e lucratividade da empresa. No caso da Yahoo a organização falhou em manter o necessário empreendedorismo de seus trabalhadores para sua lucratividade enquanto operavam remotamente, o que a levou a retornar com a modalidade de trabalho presencial $^{28}$.

Sakuda e Vasconcelos ${ }^{29}$ explicam que a convivência próxima e constante entre pessoas propicia condições mais favoráveis à criação, fortalecimento e manutenção de relações de confiança do que as relações virtuais; e a confiança é um dos fatores fundamentais para a disseminação do conhecimento tácito, de modo que, sem os cuidados necessários, o teletrabalho pode acarretar perda de conhecimento tácito ${ }^{30}$ e explícito da organização.

A criatividade e captação de conhecimento estão, portanto, vinculados à ideia de aproximação humana, convivência, notadamente nas relações profissionais. É válido um comparativo a ser realizado entre esses dois elementos típicos de qualquer atividade laboral com a prestação jurisdicional, própria do exercício do Poder Judiciário, que clama um tratamento humano, mas também técnico e científico, visto que o Direito é senão, uma ciência cuja aplicação demanda muito mais que uma aferição lógica dedutivo, mas técnico e empírico.

A Constituição Federal consagra em seu texto a inafastabilidade da tutela jurisdicional a partir do preceito insculpido no artigo $5^{\circ}$, inciso $\mathrm{XXV}$, ao estabelecer que a "lei não excluirá da apreciação do Poder Judiciário lesão ou ameaça a direito", portanto,

\footnotetext{
${ }^{28}$ ROCHA, Cháris Telles Martins da; AMADOR, Fernanda Spanier. O teletrabalho: conceituação e questões para análise. Cad. EBAPE.BR, Rio de Janeiro, v. 16, n. 1, p. 152-162, Jan. 2018 . Disponível em: http://www.scielo.br/scielo.php?script=sci_arttext\&pid=S1679-39512018000100152\&lng=en\&nrm=iso. Acesso em: 07 agosto 2020, p. 159-162.

29 SAKUDA, Luiz Ojima; VASCONCELOS, Flávio de Carvalho. Teletrabalho : desafios e perspectivas. Organ. Soc., Salvador , v. 12, n. 33, junho 2005. Disponível em: http://www.scielo.br/scielo.php?script=sci_arttext\&pid=S1984- $\quad 92302005000200002 \& \operatorname{lng}=$ en\&nrm=iso. Acesso em: 10 agosto 2020, p. 44-49.

${ }^{30}$ Conhecimento tácito é aquele que a pessoa adquiriu ao longo da vida, pela experiência.
} 
é necessário que o Judiciário não seja omisso na prestação de tutela, e que deva ser ofertada corretamente. O que resvala na possibilidade acima trazida nos estudos feitos, que a ausência de contato pessoal, pode provocar uma deficiência no conhecimento das pessoas (tácito e expresso) podendo afetar de alguma maneira a produtividade do serviço ofertado.

Assim, é necessário que, inobstante a inafastabilidade da tutela jurisdicional de caráter contínuo, conforme estabelece também a Constituição Federal em seu artigo 93, inciso XII ao consagrar que a atividade jurisdicional será ininterrupta, não podendo ela ser suspensa, tenha uma resposta célere, prática e eficaz, chamando atenção, para o atual cenário de teletrabalho imposto pelo isolamento social, para as deficiências dessa modalidade de teletrabalho.

\section{A TEMPESTIVIDADE PROCESSUAL EMTEMPOS DE PANDEMIA}

A necessidade de isolamento social demandou que toda a estrutura da Administração Pública judicante se reorganizasse para dar continuidade à prestação jurisdicional. Esse novo modelo de organização do Poder Público no período da pandemia implicou na necessidade de utilização do teletrabalho o que gera diferentes perspectivas a respeito de sua viabilidade. Para o Poder Judiciário, a pandemia tem representado um desafio não apenas pela forma e exercício das atividades, mas também em relação à manutenção da produtividade. Como conciliar a continuidade dos serviços prestados e o isolamento social, promovendo o acesso à justiça e a adequada marcha processual sem descuidar da saúde?

Por essa razão, o presente estudo procura analisar os efeitos da pandemia sobre os índices de produtividade do Poder Judiciário cearense com enfoque nos órgãos colegiados de natureza criminal (Câmaras Criminais) analisados sob a perspectiva da efetividade da prestação jurisdicional, o que se vincula diretamente às noções de celeridade processual e razoável duração do processo.

\subsection{A tempestividade processual: noções introdutórias}


O Direito brasileiro traz a previsão de celeridade processual, conferindo-lhe status de norma constitucional, conforme previsão expressa do artigo $5^{\circ}$, inciso LXXVIII, da Constituição Federal de 1988 cujo texto assim expressa: "a todos, no âmbito judicial e administrativo, são assegurados a razoável duração do processo e os meios que garantam a celeridade de sua tramitação", prevendo a celeridade e a razoável duração do processo que guardam intrínsecas ligações.

Esse dispositivo foi incluído no texto constitucional através da Emenda Constitucional de nº 45/2004 que implementou profundas mudanças no cenário jurídico do Brasil, trazendo à norma constitucional a segurança de um processo célere nos ditames da razoabilidade, congregando em um mesmo dispositivo dois institutos ao qual são conferidos natureza de princípios constitucionais que abordam direitos fundamentais independentes, com conceitos e objetivos específicos, mas ambos integrantes do processo democrático de direito constitucionalmente previsto, o que dentro do mesmo universo admitem análises individualizadas ${ }^{31}$.

A tempestividade processual é formada por uma visão tricotômica do art. $5^{\circ}$, inciso LXXVIII da CF/88, que congrega as noções de "razoável duração do processo", os "meios" conducentes à tempestividade ou, tempestividade (sob o prisma) "estrutural", "celeridade". Aqui reside o modelo de tempestividade constitucional do processo formado por essas três figuras distintas entre $\mathrm{si}^{32}$.

O primeiro deles, a razoável duração do processo consiste em um princípio de caráter harmonizador, ligado diretamente ao resultado final do processo sob o prisma do tempo, ou seja, o tempo razoável que se espera que um processo tramite do seu início ao seu trânsito em julgado. A tempestividade estrutural, segundo dos elementos acima mencionados, configura instrumentos de ordem extraprocessual que contribuem para o andamento do processo. ${ }^{33}$

\footnotetext{
${ }^{31}$ MACHADO, Lethicia Pinheiro; MORAIS, José Victor Ibiapina Cunha; PINTO, Eduardo Régis de Castro; ANDRADE, Mariana Dionísio de. A substituição dos embargos infringentes pelas técnicas de julgamento colegiado no Tribunal de Justiça do Ceará: efeitos sobre a celeridade processual. Revista Eletrônica de Direito Processual. Rio de Janeiro. a 13. v 20. n 3. set-dez. 2019. Disponível em: https://www.epublicacoes.uerj.br/index.php/redp/article/view/43986, p. 245-267.

32 DE SOUSA, José Augusto Garcia. A tríade constitucional da tempestividade do processo (em sentido amplo): celeridade, duração razoável e tempestividade estrutural. Revista de Processo, v. 280/2018, jun/2018, p. $97 / 142$.

33 Ibid.
} 
Já a celeridade processual vinculada aos demais elementos garantidores da efetividade do processo e da prestação jurisdicional adequada, está atrelada aos meios que garantem a celeridade da tramitação, mas não agindo de maneira individual a ponto de estar acima das demais garantias processuais e configurar uma celeridade absoluta ao alvedrio dos fins do próprio processo. O texto constitucional não impõe uma celeridade fulminante, geradora de um processo instantâneo, ou algo do gênero, levando em consideração o caráter dialético do processo $^{34}$, mas que garanta a eficácia da demanda pleiteada.

Essa concepção ganha especial relevo na ótica do direito processual penal, uma vez que toda sua construção e articulação de princípios se volta à busca da verdade real, onde o processo deve seguir uma concatenação estruturada de passos e procedimentos para averiguar os fatos que ocorreram e que, por terem repercussão diretamente no direito de liberdade, revestido de tamanha importância para a tutela jurisdicional, deve ser ponderado e razoável, não podendo jamais, seguir uma lógica de um procedimento excessivamente célere a ponto de prejudicar a persecução penal e condenar um inocente ou impor uma restrição ao seu exercício pleno de liberdade pela atuação desmedidamente acelerada.

Contudo, essa análise mais acurada e pormenorizada, típica do processo penal, não deve ser feita a ponto de impor ao processo uma delonga desproporcional, seja por manter aquele acusado na espera constante de uma solução para o caso que a ele imputa o cometimento de um ilícito, seja pela vítima, que espera a reparação a uma violação, função também pertencente ao processo penal.

O Código de Processo Civil de 2015 traz em seu artigo $4^{\circ}$, como um dos seus principais objetivos, a valorização da celeridade processual e razoável duração do processo, ao preceituar que, "as partes têm o direito de obter em prazo razoável a solução integral do mérito, incluída a atividade satisfativa," sendo muitas as medidas adotadas com o fim de promover a aceleração do trâmite processual, lógica que pode ser utilizada por analogia (artigo $3^{\circ}$ do Código de Processo Penal) ao processo de natureza penal, com objetivo de proporcionar a garantia do devido processo legal.

\footnotetext{
${ }^{34}$ Ibid.
} 
Assim, a verificação da efetividade de um sistema processual não tem enfoque unicamente na quantidade, na produtividade, mas demanda uma análise mais geral sob o olhar mais amplo da tempestividade processual, que trará e imporá ao processo uma concatenação de atos que formam uma sequência de procedimentos que visam a satisfação da pretensão jurisdicional de maneira eficaz, é nisso que se assenta a ideia da tempestividade processual.

A Constituição Federal traz a preocupação social de uma demanda veiculada a juízo, o que evidencia que não é apenas voltada a um aspecto processual estampada no rol de direitos e garantias fundamentais relativos ao processo. Dentre os princípios constitucionais, que se coadunam com essa interpretação destacam-se o duplo grau de jurisdição e a própria razoável duração do processo, que visam conceder, respectivamente, segurança jurídica e celeridade ao processo ${ }^{35}$.

A averiguação da celeridade de um processo não é feita por um prisma geral, mas deve ser analisada respeitando-se as peculiaridades de cada caso, pois muitas são as circunstâncias que podem contribuir para uma tramitação mais morosa de uma demanda. Macedo e Carvalho ${ }^{36}$ elencam algumas das possíveis causas, destacando que a complexidade é medida justamente por esses critérios (e não considerada por si só), tais como, o número de pessoas envolvidas no processo, o nível de complexidade das questões debatidas na lide, complexidade de fatos a serem a analisados, necessidade de realização de diligências, comportamento e boa-fé das partes, a condução do magistrado, além de perícias ou outros procedimentos complexos.

Causas faticamente complexas denotam uma instrução mais cuidadosa a exigir a produção de sentenças mais estruturadas e bem embasadas, o que implica, por conseguinte, em um aumento do custo temporal, o que reafirma a compreensão já mencionada de que uma efetiva e tempestiva prestação jurisdicional não é compreendida como aceleração do processo.

\footnotetext{
${ }^{35}$ SOUZA, Maria Carolina Rosa de. O Princípio do duplo grau de jurisdição: a compatibilidade com o princípio da celeridade processual no juizado especial cível. Revista Eletrônica de Direito Processual. Rio de Janeiro. v 9. n 9. jan. 2012. Disponível em:

https://app.vlex.com/\#/search/jurisdiction:BR/\%22celeridade+processual\%22/WW/vid/773370653 Acesso em: 10 ago 2020 , p. $525-551$

${ }^{36}$ MACEDO, Elaine Harzheim; CARVALHO, Volgane Oliveira. A duração razoável do processo no direito brasileiro e o novo código de processo civil: avanços e recuos. Revista Eletrônica de Direito Processual REDP, v. 15, n. 15, 2015, p. 81-106.
} 
Soma-se a isso a característica de recorribilidade dos atos decisórios judiciais, que pode configurar uma circunstância que aumenta o custo temporal de tramitação do processo, tendo em vista que na proporção que uma sentença é desafiada, o processo da continuidade à sua tramitação, o que ocorre em regra no Tribunal de Justiça, levando ao postergamento da tutela jurisdicional fato que pode ocasionar o perecimento do direito posto em causa, suscitando a necessidade de compatibilizar as garantias constitucionais do duplo grau de jurisdição e da razoável duração do processo, a fim de que a entrega da prestação jurisdicional seja, ao mesmo tempo, dotada de segurança jurídica e de efetividade ${ }^{37}$.

Essa preocupação mostra-se acentuada quando, em tempos de pandemia da Covid19, há a necessidade de isolamento social e a reestruturação de todo o funcionamento do Poder Público Judicial para o exercício da tutela jurisdicional em regime de teletrabalho, o que levanta inúmeros questionamentos acerca de sua viabilidade e manutenção da produtividade.

\subsection{Julgamento em números no TJCE período: quantitativos antes e pós pandemia.}

Com o objetivo de responder ao problema de pesquisa formulado, obteve-se junto às Secretarias de Câmaras Criminais $\left(1^{\mathrm{a}}, 2^{\mathrm{a}}\right.$ e $\left.3^{\mathrm{a}}\right)$ tabelas organizadas pelos respectivos setores contendo o quantitativo de processos julgados nos primeiros semestres dos anos de 2019 e 2020, nos quais foram julgados processos em expediente forense regular, com trabalho presencial e no outro foram realizadas as sessões de julgamento em regime de plantão extraordinário na modalidade de teletrabalho.

Fora formulado requerimento perante os canais de atendimento das Câmaras Criminais disponibilizados pelos setores no site do Tribunal de Justiça ${ }^{38}$ para atendimento ao público no regime do Plantão Extraordinário, obtendo as estatísticas semestrais dos órgãos julgadores nos períodos acima referidos. Os dados obtidos serão analisados a partir de um comparativo por amostragem, segregando o total de processos por Câmara Criminal (C.C.) e fazendo a análise dos períodos equivalentes em anos diferentes, sob

\footnotetext{
${ }^{37}$ SOUZA, Maria Carolina Rosa de, op. cit.

${ }^{38} \mathrm{https}$ //tjnet/tribunal-de-justica-do-ceara-disponibiliza-contatos-das-unidades-da-capital-e-interior/
} 
modalidades de trabalhos distintos para verificar se no período de teletrabalho houve efeito negativo na produtividade das câmaras com redução de seus percentuais de julgamento de natureza colegiada.

Os documentos obtidos configuram dados secundários, pois já foram organizados e coletados pelo TJCE. Os dados foram organizados ainda por tipos de recursos/ações e o quantitativo julgados ao longo de cada mês dos respectivos semestres. Dessa forma, foram selecionados os três tipos de recursos com maior índice de julgamento nas Câmaras, sendo eles apelação, recurso em sentido estrito e habeas corpus, analisados em gráficos que comparam os quantitativos de cada tipo de recurso/ação de um período por outro com o intuito de analisar mais especificamente os impactos da pandemia e do teletrabalho.

No gráfico 1 mostra um comparativo entre os dois períodos dos anos de 2019 e 2020 (primeiro semestre) das três Câmaras Criminais. No ano de 2019.1 a $1^{a}$ C.C., representada pela barra laranja, julgou um total de 2.079 processos dentre os mais variados tipos de recursos ${ }^{39}$ e/ou ações julgadas em caráter colegiado, ou seja, pelos desembargadores componentes do órgão juntos, entre os meses de janeiro a junho de 2020. A $2^{\text {a }}$ Câmara Criminal (representada pela barra em amarelo) por sua vez julgou um total equivalente a 1.499 processos em caráter colegiado, ao passo que a $3^{\text {a }}$ Câmara Criminal, representada pela barra verde, julgou em colegiado, um total de 1.870 processos, nas mesmas categorias de recursos e ações dos demais órgãos.

No segundo conjunto de barras, na parte superior do gráfico acima, há a representação numérica dos julgados dos respectivos órgãos colegiados no primeiro semestre de 2020, indicando que 2.396 processos julgados pela $1^{\text {a }}$ C.C., o que demonstra não só que a existência do Plantão Extraordinário não afetou negativamente a sua produtividade, como impulsionou o aumento de aproximadamente $15 \%$ dos seus índices de julgamento.

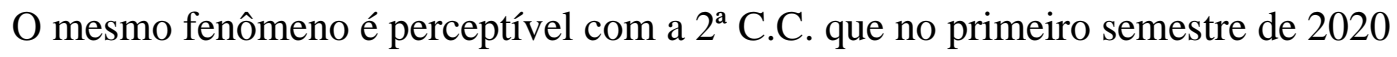
julgou um total de 2.308 processos, configurando um aumento de aproximadamente $54 \%$

\footnotetext{
${ }^{39}$ Apelação, Recurso em Sentido Estrito (RESE), Agravo em Execução Penal, Habeas Corpus (HC), Reexame Necessário, Agravo Regimental, Embargos de Declaração, Conflito de Jurisdição, Mandado de Segurança, Petição de Reclamação, Exceção de Suspeição, Correição Parcial e Carta Testemunhável, Restituição de Coisas Apreendidas, Incidente de Insanidade.
} 
de sua produtividade de um semestre para o outro, justamente na modalidade de teletrabalho imposto pelo regime de Plantão Extraordinário. A $3^{\text {a }}$ C.C. julgou no primeiro semestre de 2020 um total de 2.339 processos, representando um aumento de aproximadamente $25 \%$ de sua produtividade com a adoção de seus julgadores e servidores à modalidade de teletrabalho, seguindo o mesmo parâmetro das demais câmaras de aumento dos números.

Os gráficos 2 e 3 evidenciam o mesmo comparativo nas modalidades de recursos/ações. Para mostrar de forma mais didática e evidente os impactos da mudança de modalidade de trabalho (presencial para teletrabalho) foram selecionados os três tipos com maior quantitativo de julgados: apelação, recurso em sentido estrito (RESE) e habeas corpus (HC).

A $1^{\text {a }}$ C.C. no primeiro semestre de 2019 julgou um total de 1.106 apelações, 699 habeas corpus, 130 RESE's. Já no primeiro semestre de 2020, julgou 1.205 apelações, 942 habeas corpus e 125 RESE's; evidenciando um aumento em duas das três categorias de processos selecionadas para este segundo comparativo, não havendo diminuição no quantitativo de processos julgados. Já a 2 ${ }^{\text {a }}$ C.C. julgou 426 apelações, 791 habeas corpus e 156 RESE's no primeiro semestre de 2019, ao passo que no mesmo período de 2020, julgou 1.026 apelações, 1.028 habeas corpus e 146 RESE's, mostrando um aumento do quantitativo nas duas categorias de processos, que de igual forma configuram um aumento do número de julgados no âmbito geral.

A $3^{\text {a }}$ C.C. julgou 911 apelações, 751 habeas corpus e 98 RESE's no primeiro semestre do ano de 2019, ao passo que no mesmo período de 2020 julgou 1.058 apelações, 1.026 habeas corpus e 108 RESE's, evidenciando um aumento nas três categorias de recursos/ações acima selecionados, demonstrando, mais uma vez, que a adoção da modalidade do teletrabalho não impactou negativamente na produtividade dos órgãos selecionados para esta pesquisa.

\section{CONCLUSÃO}

Conclui-se, portanto, que as medidas de isolamento social impostas para combater a proliferação do Covid-19 não afetou negativamente os indicadores de produtividade do 
Tribunal de Justiça do Estado do Ceará. Portanto, mesmo atendendo às determinações governamentais e suspendendo suas atividades presenciais, necessitando se reestruturar para dar continuidade na prestação da atividade jurisdicional que por comando constitucional é ininterrupta, o Poder Judiciário cearense conseguiu encontrar alternativas para manter a produtividade.

Dentre as medidas adotadas para manutenção das atividades destaca-se à adoção ao teletrabalho. Estudos apontam que os trabalhadores veem no geral de maneira positiva a viabilidade do regime de trabalho, que já está amplamente difundido ao redor do globo e com a pandemia houve uma aceleração de sua implementação. Portanto, os aspectos comumente tidos como negativos a partir dos estudos trazidos não classifica o teletrabalho como uma medida ineficaz e que traz prejuízos para as instituições, ressalvadas algumas peculiaridades.

O Tribunal de Justiça do Ceará, visando dar continuidade ao exercício da atividade judicante substituiu suas sessões de julgamento presenciais para a modalidade por videoconferência, impondo o regime de Plantão Extraordinária na esteia do que regulamentou o Conselho Nacional de Justiça em âmbito nacional, o que suscitaria duvidas acerca de sua viabilidade já que essa modalidade implica na adoção do teletrabalho.

A grande incerteza da inviabilidade dessas medidas volta-se à manutenção da produtividade do judiciário e consequentemente a efetividade da prestação jurisdicional. A eficácia é analisada sob a perspectiva da tempestividade processual, que congrega os conceitos de celeridade, razoável duração do processo e os mecanismos extraprocessuais aptos a assegurarem a efetiva prestação jurisdicional.

Portanto, a prestação jurisdicional se mostra eficaz quando a tramitação dos processos, atendendo às suas peculiaridades de cada caso, dentro dos parâmetros de uma razoável duração que não pode implicar em uma aceleração desmedida ao arrepio das demais garantias constitucionais a partir da utilização dos mecanismos postos a serviço das instituições judicantes pelo legislador de ordem endoprocessual e extraprocessual. Com isso, os processos tramitação de maneira a garantir a efetividade das tutelas buscadas pelas partes envolvidas com impacto direto nos índices de produtividade de uma unidade judiciária. 
É possível classificar o teletrabalho $\mathrm{e}$ as sessões de julgamento por videoconferência como mecanismos adequados e praticados pelo TJCE com vistas a garantir a efetividade de sua atuação e manter a produtividade. Com o objetivo de responder ao problema de pesquisa formulado, analisando a produtividade das Câmaras Criminais em atuação colegiada, verificou-se que a $1^{\text {a }}$ C.C. aumentou sua produtividade em aproximadamente $15 \%$, afetando positivamente os índices de julgamentos; a $2^{\mathrm{a}}$ C.C. que no ano de 2020.1 alcançou um aumento expressivo de aproximadamente $54 \%$ de sua produtividade de um semestre para o outro; e a $3^{\text {a }}$ C.C. julgou no ano de 2020.1 aproximadamente $25 \%$ a mais que no mesmo período do ano anterior, mostrando um aumento de sua produtividade com a adoção às sessões de julgamento por videoconferência no teletrabalho.

Portanto, a resposta ao problema de pesquisa se mostra afirmativa uma vez que as medidas adotadas pelo TJCE em meio à pandemia da Covid-19 mostraram-se eficazes não apenas para garantir a manutenção da produtividade das Câmaras Criminais (objeto de análise deste trabalho), mas também para o aumento dos números de processos julgados.

Isso leva à compreensão que na análise desenvolvida a tempestividade processual fora respeitada, uma vez que não houve uma diminuição do número de processos julgados em face das circunstâncias acarretando uma demora no julgamento daqueles que não viessem a ser julgados, atendendo, portanto, à não violação no âmbito geral da razoável duração e celeridade processuais com medidas úteis de garantia desses comandos constitucionais, tripé da compreensão constitucional da tempestividade processual.

\section{REFERÊNCIAS}

BRASIL. Lei no 12.551 , de 15 de dezembro de 2011. Altera o art. $6^{\circ}$ da Consolidação das Leis do Trabalho (CLT), aprovada pelo Decreto-Lei n ${ }^{\circ} 5.452$, de $1^{\circ}$ de maio de 1943, para equiparar os efeitos jurídicos da subordinação exercida por meios telemáticos e informatizados à exercida por meios pessoais e diretos.. Lei $\mathbf{N}^{\mathbf{0}}$ 12.551. Brasília, DF, 16 dez. 2020. 
BRASIL. Constituição da República Federativa do Brasil. Senado Federal, Brasília, 1988.

BRASIL. Resolução n 313, de 19 de março de 2020. Estabelece, no âmbito do Poder Judiciário, regime de Plantão Extraordinário, para uniformizar o funcionamento dos serviços judiciários, com o objetivo de prevenir o contágio pelo novo Coronavírus Covid-19, e garantir o acesso à justiça neste período emergencial. Resolução No 313. Brasília, DF, 19 mar. 2020. Disponível em: https://atos.cnj.jus.br/atos/detalhar/3249. Acesso em: 20 jul. 2020

BRASIL. Resolução no 314, de 20 de abril de 2020. Prorroga, no âmbito do Poder Judiciário, em parte, o regime instituído pela Resolução no 313, de 19 de março de 2020, modifica as regras de suspensão de prazos processuais e dá outras providências. Resolução No 314. Brasília, DF, 20 abr. 2020. Disponível em: https://atos.cnj.jus.br/atos/detalhar/3283. Acesso em: 20 jul. 2020

CEARÁ. Decreto no 33.519, 19 de março de 2020. Intensifica as medidas para enfrentamento da infecção humana pelo novo coronavírus. Fortaleza. Disponível em: https://www.cge.ce.gov.br/wp-content/uploads/sites/20/2020/03/Decreto-n.33.519-de-19-de-mar\%C3\%A7o-de-2020.-Intensifica-as-medidas-paraenfrentamento-da-infec\%C3\%A7\%C3\%A3o-humana-pelo-novo-coronavirus.pdf

CEARÁ. Boletim Epidemiológico Doença pelo novo coronavírus (COVID-19). Secretaria de Saúde do Estado do Ceará. Fortaleza. 12 de maio de 2020. Disponível em: https://www.saude.ce.gov.br/wpcontent/uploads/sites/9/2020/02/boletim_Covid_n25_12_05_2020_v2.pdf. Acesso em: 18 jul. 2020.

CEARÁ. Boletim Epidemiológico Doença pelo novo coronavírus (COVID-19).

Secretaria de Saúde do Estado do Ceará. Fortaleza. 09 julho de 2020. Disponível em: https://www.saude.ce.gov.br/wpcontent/uploads/sites/9/2020/02/BOLETIM_COVID_09_07_2020.pdf. Acesso em: 18 jul. 2020.

CEARÁ. Resolução $\mathrm{n}^{\circ}$ 26, 04 de outubro de 2018. Disciplina o funcionamento do voto provisório no âmbito do Poder Judiciário do Estado do Ceará. Fortaleza. 
Disponível em: https://sistemas-

internet.tjce.jus.br/includes/mostraAnexo.asp?san=24584. Acesso em: 23 jun. 2020.

CEARÁ. Portaria n ${ }^{\circ} 635$, de 22 de abril de 2020. Autoriza a realização de sessão de julgamento por videoconferência, em substituição às sessões presenciais, no âmbito do Poder Judiciário do Estado do Ceará. Portaria Nº 635. Fortaleza, CE, 22 abr. 2020 .

CEARÁ. Portaria n ${ }^{\circ} 514$, de 23 de março de 2020. Regulamenta, no âmbito do Poder Judiciário do Estado do Ceará, o regime de Plantão Extraordinário, estabelecido pela Resolução n 313, de 19 de março de 2020, do Conselho Nacional de Justiça. Portaria No 514. Fortaleza, CE, 23 mar. 2020.

CEARÁ. Portaria nº 563, de 31 de março de 2020. Autoriza a realização de sessão de julgamento por videoconferência no âmbito do Poder Judiciário do Estado do Ceará. Portaria No 563. Fortaleza, CE, 31 mar. 2020.

CNJ. Conselho Nacional de Justiça. Relatório Justiça em Números 2020. Disponível em: https://www.cnj.jus.br/wp-content/uploads/2020/08/WEB-V3-Justiça-em-Números2020-atualizado-em-25-08-2020.pdf. Acesso em: 01 set. 2020.

FERREIRA, Aurélio Buarque de Holanda. Novo Aurélio Século XXI: o dicionário da língua portuguesa. 3. ed. Rio de Janeiro: Nova Fronteira, 1999.

FILARDI, Fernando; CASTRO, Rachel Mercedes P. de; ZANINI, Marco Tulio Fundão. Vantagens e desvantagens do teletrabalho na administração pública: análise das experiências do Serpro e da Receita Federal. Cad. EBAPE.BR, Rio de Janeiro, v. 18, n. 1, p. 28-46, Jan. 2020 . Disponível em: http://www.scielo.br/scielo.php?script=sci_arttext\&pid=S167939512020000100028\&lng=en\&nrm=iso. Acesso em: 07 ago 2020.

MACEDO, Elaine Harzheim; CARVALHO, Volgane Oliveira. A duração razoável do processo no direito brasileiro e o novo código de processo civil: avanços e recuos.

Revista Eletrônica de Direito Processual - REDP, v. 15, n. 15, 2015, p. 74-106. Disponível em: https://www.epublicacoes.uerj.br/index.php/redp/article/view/16865. Acesso em: 07 ago 2020. MACHADO, Lethicia Pinheiro; MORAIS, José Victor Ibiapina Cunha; PINTO, Eduardo Régis de Castro; ANDRADE, Mariana Dionísio de. A substituição dos embargos 
infringentes pelas técnicas de julgamento colegiado no Tribunal de Justiça do Ceará: efeitos sobre a celeridade processual. Revista Eletrônica de Direito Processual. Rio de Janeiro. a 13. v 20. n 3. set-dez. 2019. Disponível em: https://www.epublicacoes.uerj.br/index.php/redp/article/view/43986

OPAS BRASIL. Organização Pan-Americana de Saúde. Folha informativa - COVID-19 (doença causada pelo novo coronavírus). 23 de abril de 2020. Disponível: https://www.paho.org/bra/index.php?option=com_content\&view=article\&id=6101:C ovid19\&Itemid=875. Acesso em: 11 jul. 2020.

Quase 100 dias após anúncio da Covid-19, mundo tem mais de 74 mil mortes. Onu News. 8 de abril de 2020. Disponível em: https://news.un.org/pt/story/2020/04/1709852. Acesso em: 11 jul. 2020.

ROCHA, Cháris Telles Martins da; AMADOR, Fernanda Spanier. O teletrabalho: conceituação e questões para análise. Cad. EBAPE.BR, Rio de Janeiro, v. 16, n. 1, p. 152-162, Jan. 2018 . Disponível em: http://www.scielo.br/scielo.php?script=sci_arttext\&pid=S167939512018000100152\&lng=en\&nrm=iso. Acesso em: 07 ago. 2020.

ROTHAN, Hussin A.; BYRAREDDY, Siddappa N. The epidemiology and pathogenesis of coronavirus disease (COVID-19) outbreak. Journal of Autoimmunity. 2020. Disponível em: file://C:/Users/Joao\%20Vitor/Downloads/The\%20epidemiology\%20and\%20pathog enesis\%20of\%20coronavirus\%20disease\%20(COVID-19)\%20outbreak..pdf

SAKUDA, Luiz Ojima; VASCONCELOS, Flávio de Carvalho. Teletrabalho : desafios e perspectivas. Organ. Soc., Salvador, v. 12, n. 33, p. 39-49, junho 2005. Disponível em: http://www.scielo.br/scielo.php?script=sci_arttext\&pid=S198492302005000200002\&lng=en\&nrm=iso. Acesso em: 10 ago. 2020.

SOUSA, José Augusto Garcia de. A tríade constitucional da tempestividade do processo (em sentido amplo): celeridade, duração razoável e tempestividade estrutural.

Revista de Processo, v. 280/2018, jun/2018, p. 95/142.

SOUZA, Maria Carolina Rosa de. O Princípio do duplo grau de jurisdição: a compatibilidade com o princípio da celeridade processual no juizado especial cível. Revista Eletrônica de Direito Processual. Rio de Janeiro. v 9. n 9. jan. 2012. 
Disponível em:

https://app.vlex.com/\#/search/jurisdiction:BR/\%22celeridade+processual\%22/WW/v id/773370653

World Health Organization. Coronavirus desease (COVID-19) situation reports.

Disponível em: https://www.who.int/emergencies/diseases/novel-coronavirus-

2019/situation-reports Acesso em: 11 jul. 2020

World Healthy Organization. Novel Coronavirus (2019-nCov). Situation Report - 52.

Disponível em: https://www.who.int/emergencies/diseases/novel-coronavirus2019/situation-reports. Acesso em: 11 jul. 2020.

\section{Gráfico 1 - Produtividade semestral das Câmaras Criminais (C.C.)}

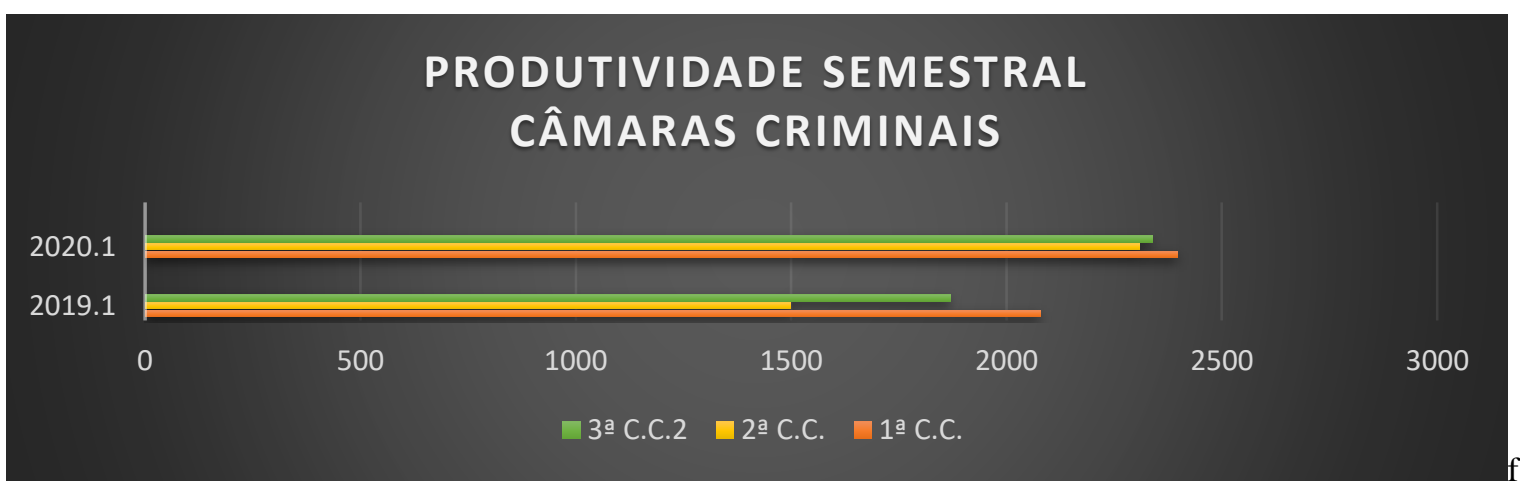

Fonte: Elaboração própria.

Gráficos 2 e 3 - Produtividade das Câmaras Criminais (C.C.) por recurso (2019.1 e 2020.1) 
Revista Eletrônica de Direito Processual - REDP.

Rio de Janeiro. Ano 15. Volume 22. Número 2. Maio a Agosto de 2021

Periódico Quadrimestral da Pós-Graduação Stricto Sensu em Direito Processual da UERJ

Patrono: José Carlos Barbosa Moreira (in mem.). ISSN 1982-7636. pp. 469-496 www.redp.uerj.br

\section{Produtividade Câmaras \\ por recurso - 2019.1}

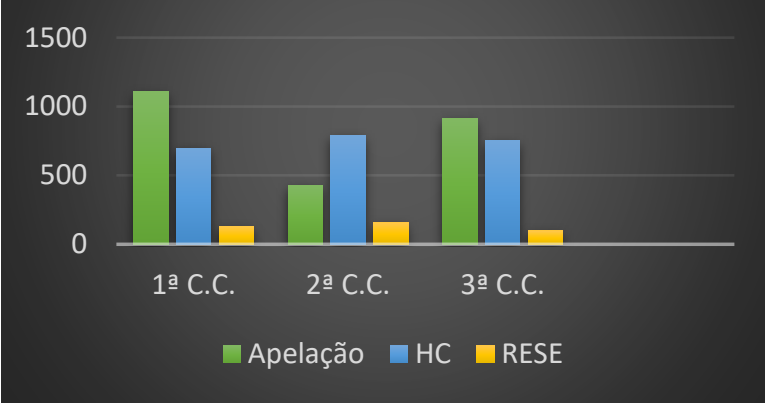

\section{Produtividade Câmaras} por recurso - 2020.1

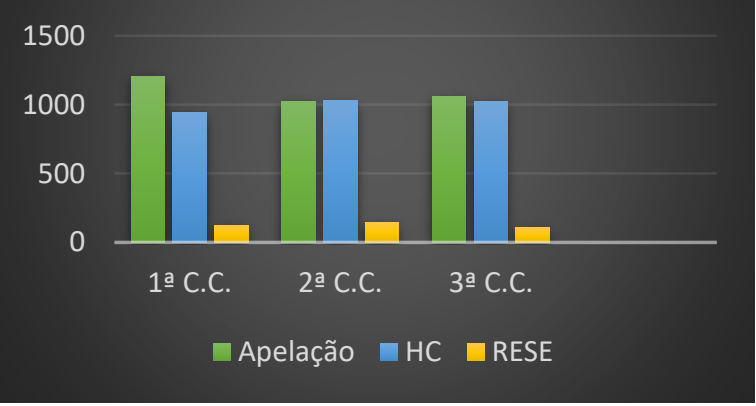

Fonte: Elaboração própria. 